\title{
Anti-carcinogenic Activities of Different Extracts of Arum rupicola Boiss. var. rupicola from Turkey ${ }^{\dagger}$
}

\author{
Imge Kunter*, Ezgi Ak, Beste Atli, Nesrin Oztinen, Andia Babri and Muberra Kosar \\ Faculty of Pharmacy, Eastern Mediterranean University, North Cyprus via Mersin 10, 99628 Famagusta, \\ Turkey; ezgiiakk@hotmail.com (E.A.); beste.atli@gmail.com (B.A.); nesrinnesrinoztinen@gmail.com (N.O.); \\ andiababri72@gmail.com (A.B.); muberra.kosar@emu.edu.tr (M.K.) \\ * Correspondence: imge.kunter@emu.edu.tr; Tel.: +90-392-630-2868 \\ + Presented at the 3rd International conference on Natural Products for Cancer Prevention and Therapy, \\ Kayseri, Turkey, 18-20 December 2019.
}

Published: 26 December 2019

\begin{abstract}
The Arum L. in the Araceae family belongs to flowering plants. It is represented by 14 species and four varieties. In total, there are 18 taxa in Turkey. Arum rupicola Boiss. var. rupicola is one of taxa among them. Traditionally, boiled and dried leaves are used as food supplement in folk medicine in Turkey. In our previous study, the results showed that different extracts of tubers have varying levels of anticholinesterase activity. In this study, anti-carcinogenic activities were evaluated of the hexane, ethyl acetate, $70 \%$ methanol and distilled water extracts of $A$. rupicolaa var. rupicola on SK-HEP-1 adenocarcinoma cell line. MTT and wound healing assays were used to assess cytotoxicity and 2D cell motility, respectively. Results showed that distilled water extract has the maximum potency and consistent cytotoxic and anti-motility effects on SK-HEP-1 cells.
\end{abstract}

Keywords: Arum rupicola var. rupicola; Araceae; cytotoxicity

(C) 2019 by the authors. Licensee MDPI, Basel, Switzerland. This article is an open access article distributed under the terms and conditions of the Creative Commons Attribution (CC BY) license (http://creativecommons.org/licenses/by/4.0/). 